\title{
The application of finite element analysis as a new approach in corrosion and integrity assessment programs
}

\begin{abstract}
Structural integrity assessment procedures are interesting areas in many industrial plants, e.g., oil and gas, and petrochemical for ensuring the safety and economy of an operating sector. The remaining strength of components (e.g. pipelines, risers) with corrosion defects is a prevalent project in the oil and gas industry, and it has been investigated for years via using experimental, numerical and analytical methods. Obtaining the stress distribution in the vicinity of corrosion defects is a decisive phase in understanding the structural integrity of corroded components under high internal pressure. In the corrosion based management programs, finite element analysis (FEA) can provide valuable results in the integrity assessment. Also, FEA can be applied to corrosion monitoring of structures by considering different parameters such as protecting current distribution, electrochemical potential grid and coating degradation. This research discusses the application of FEA in the corrosion and integrity assessment process based on three areas including, in-service performance of corroded parts, repairing methods and corrosion monitoring techniques.
\end{abstract}

Volume 2 Issue I - 2017

\author{
Sadeq Hooshmand Zaferani \\ Department of Petroleum Engineering, Petroleum University of \\ Technology, Iran
}

Correspondence: Sadeq Hooshmand Zaferani, Department of
Petroleum Engineering, Petroleum University of Technology, Iran, Tel +98-910-456-63I2, Email S-hooshmand@hotmail.com

Received: November 23, 2016 | Published: February 02, 2017

Keywords: corrosion assessment, finite element analysis, structural integrity

Abbreviations: FFS: fitness for Service; FAD: failure assessment diagram; FEA: finite element analysis; CIC: crack in corrosion; FEM: finite element method; SCF: stress concentration factors; ANN: artificial neural networks; LEFM: linear elastic fracture mechanics; FRP: fiber reinforced polymer

\section{Introduction}

Due to the explosive characteristics of gas and oil, providing a structural integrity is a vital requirement in those industries. Also, the economical and environmental considerations tend to the structural integrity and safety assessment. Therefore, reliable structural integrity and safety of oil and gas structures such as transmission pipelines under different service conditions, especially including the presence of defects (e.g. Corrosion defects, gouges, foreign object scratches and pipeline erection activities) must be determined..$^{1-3}$

In this field, fitness-for-service (FFS) assessment is chiefly carried out to depict the integrity of ageing pressure components (e.g.: pipelines) and structures with defects in order to evaluate the acceptability for sustained service and estimate their remaining life. Some of the FFS assessment procedures including, API 579, BS 7910 use the failure assessment diagram (FAD) as the most common methods for assessing cracks in pipelines at three different levels based on the available material information. Moreover, the structural integrity assessment procedure for European industry procedure (SINTAP) is based on the failure assessment diagram (FAD), as well. ${ }^{3-5}$

Furthermore, several standards have been developed for failure assessment of corroded pipelines. In this field, ASME B31G is used for determining the remaining strength of the corroded pipelines. Also, a uniform guideline DNV RP F101 was established on the basis of full-scale experimental tests and finite element analysis (FEA). ${ }^{6,7}$ It's a helpful code for pipeline corrosion defect assessment and provides guidance for both internal pressure and combined loading.

Finite element analysis (FEA) as a useful tool has been utilized for demonstrating the accurate limit loads of pipelines containing corrosion defects. Also, FEA is capable of analyzing more complex shapes and situations such as multiple corrosion defects and complicated corrosion defects. ${ }^{8}$ As a result, by developing of theory and required hardware of finite element method (FEM), numerical simulation was employed to examine the local details of structure. ${ }^{9}$

\section{Corrosion defects analysis}

On the basis of the operating conditions of oil and gas structural components (e.g.: risers, piles and pipelines) in harsh areas such as marine environment, various damage scenarios can be caused. Coating damage, corrosion, erosion and mechanical damage are widespread in both construction and operation projects. ${ }^{10}$

Obtaining the stress distribution in the proximity of corrosion defect is the most important step in the structural integrity of corroded pipelines. Also, due to the defect dimensions (length, width, depth, width to length ratios) and their status as a single or colony, the evaluation strategies will vary. In this field, on the basis of the FEA results, using of plastic collapse or the stress distribution level of the cross-section below the deepest point of the defect area is functional in the integrity assessment programs. Consequently, the stress was appraised in comparison of a settled reference stress value (component of the stress-strain behavior) which represents the failure stress of the defective pipe. ${ }^{11}$

TA Netto et al. ${ }^{12}$ studied the effects of corrosion defects on the collapse pressure of offshore pipelines through the combination of small-scale experiments with nonlinear numerical analyses based on 
FEA. The model was performed to assess the collapse pressure on the basis of material and geometric factors for various pipes and defects.

In the integrity assessment, identifying the defect shapes is considered as a crucial factor to catch the reliable results. D Cronin et al. ${ }^{5}$ evaluated hybrid defect (Crack-in-Corrosion or CIC)in pipelines. They accomplished the finite element method, using an elastic-plastic fracture mechanics for predicting the failure pressures of comparable crack, corrosion and CIC in order to depict the failure response of those defects.

As another matter, pitting corrosion is supposed as an important type of defect which needs to be determined among the integrity assessment via the stress distribution evaluation. There are various studies, in which the pit corrosion defects were investigated by FEA. JE AbdallaFilho et al. ${ }^{8}$ used FEA to propose an analytical procedure in order to calculate the failure pressure regarding to isolated pits. In another research, ${ }^{13}$ the stress concentration factors (SCF) of the isolated elliptical corrosion pits were investigated by using 3-D finite element analyses. In this study, the elliptical pits were evaluated associating to their 3-D geometries (both diameters and pit depth) through a series of parametric studies of finite element pipe models on behalf of quantifying the effect of geometric changes of the pits on SCF.

Recently, artificial neural networks (ANN) have attracted a lot of attention due to their application in the engineering fields. In the corrosion and integrity assessment, MK Khalajestani et al. ${ }^{14}$ studied the effects of material and geometric factors of an elbow with a single defect by means of a vast nonlinear parametric FEA and ANN, afterwards. In this research, the authors carried out a huge amount of database of limit pressure capacities by three-dimensional FEA in order to represent a comprehensive solution in the form of an ANN and proscribe the limit pressure capacity of corroded elbows under the internal pressure. Also, RCC Silva et al. ${ }^{15}$ showed an application of the ANN for the assessment of pipes with interacting defects. Finite element simulations were used on a pipe containing two aligned and equally shaped defects with different defects spacing in order to make a database depicting the relation between the failure pressures of pipes with single and multiple defects. Also, final neural networks results were compared with the derived results from the DNV RP-F101 code.

\section{Repairing techniques analysis}

Generally, the integrity assessment and repairing techniques are depending on defect type. A major problem for the oil and gas industry is the repair of corroded steel piping in which the replacement of affected sections usually needs high expenses and safety strategies. Therefore, the alternatives rather than the hot works (e.g.: welding) have been widely investigated due to their advantages including

i. Less time required for repairing,

ii. No undisrupted fluid transmission among the repair process, and

iii. Declining the explosion potential by elimination of welding or cutting of the pipeline. ${ }^{16}$

Thus, it is necessary to analyze the application of the repair systems via the numerical techniques to assure about the final performance.

Recently, adhesively bonded joints have been considered as an important application field in the marine and offshore industry. The adhesive repairing composite patches are a charming alternative, which require to be appraised through the strength of bonded steelcomposite joints. Consequently, fracture-based finite element formulations have been developed in order to proscribe the adhesive joint strength. There are various models which can demonstrate the initiation and propagation of cracks within the cohesive zone and represent and execute as user-defined functionality among the computer codes. In this field, FEA can use the cohesive elements for the adhesive bond line as a powerful tool for strength predictions of adhesively bonded joints. ${ }^{17}$

The fibre reinforced polymer (FRP) matrix composite over wrap systems have been made to prevent external corrosion and structurally reinforced steel pipes by external wrapping of damaged parts. J.M. Duell et al. ${ }^{18}$ characterized several defect geometries (in different circumferential lengths) with their pertaining corrosion patches on the steel pipe by using FEA.

In other research, MF Köpple et al. ${ }^{10}$ applied Linear Elastic Fracture Mechanics (LEFM) and FEA to study the detachment of the FRP overwrap from the steel substrate. On the basis of ISO-24817 and ASME PCC-2, N Saeed et al. ${ }^{19}$ assessed the effect of operating pressure on repair thickness design by employing the analytical equations and finite element method and showed the repair thickness is independent of the live pressure; therefore, a proper modification was proposed to the existing design equation.

\section{Corrosion monitoring techniques}

Continuous monitoring of structure (e.g. transmission pipeline, offshore platforms), determination their status and considering them among the corrosion and integrity assessment are essential to ensure their safety and sustained operation. On the other hand, by providing more input to the assessment process, the final results will be more accurate. FEA method can ameliorate the application of testing and monitoring techniques by providing more details which leads to better understanding of the structure condition. Recently, W Duan et al. ${ }^{20}$ has used a hybrid Semi-Analytical FE approach to model scattering from non-axisymmetric defects in coated pipes in order to set a better comprehension of ultrasonic guided waves propagation in the coated pipes. Another research ${ }^{21}$ depicted the experimental results and finite element method (FEM) models which showed the ability of ultrasonic surface waves to test components with potential of developing stress corrosion cracking, in order to identify and characterize surfacebreaking defects. They carried out varied branched geometries to simulate SCC type defects and evaluated the geometry by using laserbased ultrasonic generation and detection of Rayleigh waves.

In continues, the corrosion mapping and development of an electrochemical potential and current distribution grid can be introduced as the helpful techniques. Ghadala et al. ${ }^{22}$ developed a finite element model for the external corrosion of buried steel pipelines at coating failures in order to anticipate the coating degradation among various soil and cathodic protection $(\mathrm{CP})$ conditions. Also, the interactions between different important factors, including steadystate temperature, potential, and oxygen concentration profiles in the soil surrounding the pipeline structure were determined. The results depicted the geometric location of the coating breakdown site relative to the ground surface and the $\mathrm{CP}$ anode brings a specific influence on oxygen concentration profiles and pipeline corrosion. In another study ${ }^{23}$ a computer software with finite element capability was used to investigate the design of $\mathrm{CP}$ systems in which the influences of 
electrical conductivity of soil and impressed current density of the potential distribution were studied and the optimum impressed current density was determined for various soil conductivities.

Application of FEA is important in developing of such a grid and can cover the entire external structure subjected to the corrosive conditions. By developing the grid, the coating degradation and high requiring currents (e.g.: an FEA map of the potential) can be detected and nominated as the specific risky locations or threats.

\section{Conclusion}

Finite element analysis (FEA) can improve the corrosion and integrity assessment process via:

I. Accurate measurement of burst pressure of corroded pipeline and also evaluation of the effect of defect geometries on the operating pressure;

II. Providing the assessment techniques in order to investigate the repairing methods and their capabilities;

III. Enhancing the monitoring techniques via ameliorating the testing methods or making more input data by establishing the required grid.

\section{Acknowledgements}

None.

\section{Conflict of interest}

The author declares no conflict of interest.

\section{References}

1. H Adib, S Jallouf, C Schmitt, et al. International Journal of Pressure Vessels and Piping. 2007;84(3):123-131.

2. AP Teixeir, C GuedesSoares, TA Netto, et al. International Journal of Pressure Vessels and Piping. 2008;85(4):228-237.

3. H Adib-Ramezani, J Jeon, G Pluvinage. International Journal of Pressure Vessels and Piping. 2006;83(6):420-432.

4. MM Hossain, R Seshadri. International Journal of Pressure Vessels and Piping. 2010;87(7):381-388.

5. B Bedairi, D Cronin, A Hosseini, et al. International Journal of Pressure Vessels and Piping. 2012;96-97:90-99.

6. Y Chen, H Zhang, J Zhang, et al. Failure analysis of high strength pipeline with single and multiple corrosions. Materials and Design. 2015;67:552-557.

7. B Ma, J Shuai, D Liu, et al. Assessment on failure pressure of high strength pipeline with corrosion defects. Engineering Failure Analysis. 2013;32:209-219.

8. JE Abdalla Filho, RD Machado, RJ Bertin, et al. On the failure pressure of pipelines containing wall reduction and isolated pit corrosion defects. Computers and Structures. 2014;132:22-33.
9. T Wang, JG Yang, XS Liu, et al. Stress intensity factor expression for butt joint with single-edge crack considering the effect of joint shape. Materials and Design. 2012;36:748-756.

10. MF Köpple, S Lauterbach, W Wagner. Composite repair of through-wall defects in pipe work - Analytical and numerical models with respect to ISO/TS 24817. Composite Structures. 2013;95:173-178.

11. G Fekete, L Varga. The effect of the width to length ratios of corrosion defects on the burst pressures of transmission pipelines. Engineering Failure Analysis. 2012;21:21-30.

12. TA Netto, US Ferraz, A Botto. On the effect of corrosion defects on the collapse pressure of pipelines. International Journal of Solids and Structures. 2007;44(22-23):7597-7614.

13. J Ji, C Zhang, J Kodikara, et al. Prediction of stress concentration factor of corrosion pits on buried pipes by least squares support vector machine. Engineering Failure Analysis. 2015;55:131-138.

14. MK Khalajestania, MR Bahaaria, A Salehib, et al. Predicting the limit pressure capacity of pipe elbows containing single defects. Applied Ocean Research. 2015;53:15-22.

15. RCC Silva JNC Guerreiro, AFD Loula. A study of pipe interacting corrosion defects using the FEM and neural networks. Advances in Engineering Software. 2007;38(11-12):868-875.

16. H Osnes, D McGeorge, JR Weitzenbock, et al. Predicting failure of bonded patches using a fracture mechanics approach. International Journal of Adhesion \& Adhesives. 2012;37:102-111.

17. F Hernandez Valle, B Dutton, RS Edwards. Laser ultrasonic characterization of branched surface-breaking defects. NDT\&E International. 2014;68:113-119.

18. JM Duell, JM Wilson, MR Kessler. Analysis of a carbon composite overwrap pipeline repair system. International Journal of Pressure Vessels and Piping. 2008;85(11):782-788.

19. N Saeed, H Ronagh, A Virk. Composite repair of pipelines, considering the effect of live pressure-analytical and numerical models with respect to ISO/TS 24817 and ASME PCC-2. Composites:Part B. 2014;58:605610 .

20. W Duan, R Kirby, P Mudge. On the scattering of elastic waves from a non-axisymmetric defect in a coated pipe. Ultrasonics. 2016;65:228241.

21. MH Parsa, SR Allahkaram, AH Ghobadi. Simulation of cathodic protection potential distributions on oil well casings. Journal of Petroleum Science and Engineering. 2010;72(3-4):215-219.

22. IM Gadala, MA Wahab, A Alfantazi. Numerical simulations of soil physicochemistry and aeration influences on the external corrosion and cathodic protection design of buried pipeline steels. Materials \& Design. 2016;97(5):287-299.

23. Risk based corrosion management. 2015. 